\title{
Criatividade aberta: proposição teórica de análise a partir dos espaços de coworking
}

\author{
Open creativity: theoretical proposition of analysis from the coworking spaces \\ Creatividad abierta: proposición teórica de análisis a partir de los espacios de \\ coworking
}

Henrique Muzzio ${ }^{1}$

Recebido em 11/05/2018; revisado e aprovado em 30/10/2018; aceito em 04/11/2018

DOI: http://dx.doi.org/10.20435/inter.v20i4.1982

\begin{abstract}
Resumo: Este trabalho apresenta uma proposição teórica sobre a criatividade aberta, definida como a capacidade de gerar e aprimorar ideias a partir da colaboração com agentes externos. A criatividade aberta é entendida como um fenômeno independente e antecedente à inovação. Utilizando os ambientes de coworking como lócus de análise, onde se realiza uma intensa troca de ideias e de capital social.
\end{abstract}

Palavras-chaves: acriatividade; criatividade aberta; coworking.

Abstract: This paper presents a theoretical proposition about open creativity, defined as the ability to generate and improve ideas through collaboration with external agents. Open creativity is understood as an independent phenomenon and antecedent to innovation. We use the coworking environments as a locus of analysis, where intense exchanges of ideas and social capital take place.

Keywords: creativity; open creativity; coworking.

Resumen: Este trabajo presenta una proposición teórica sobre la creatividad abierta, definida como la capacidad de generar y perfeccionar ideas a partir de la colaboración con agentes externos. La creatividad abierta se entiende como un fenómeno independiente e antecedente de la innovación. Utilizamos los ambientes de coworking como locus de análisis, donde se realizan intensos intercambios de ideas y de capital social.

Palabras clave: creatividad; creatividad abierta; coworking.

\section{INTRODUÇÃO}

O objetivo deste artigo é apresentar uma proposição teórica sobre uma nova terminologia na literatura, a criatividade aberta, que definimos como a capacidade de gerar e aprimorar ideias a partir da inspiração e/ou colaboração com agentes externos, por meio de parcerias formais ou informais, ocorridas em contextos físicos ou virtuais, que tem como intuito a ampliação da capacidade de inovar de indivíduos ou de firmas. Utilizaremos como contexto de análise os espaços de coworking, locais de trabalho coletivo utilizados por profissionais de diversas organizações e campos de conhecimento, o que possibilita amplificar a diversidade das conexões externas e seus potenciais benefícios. Reconhecemos que esses ambientes não são exclusivos para a existência de colaboração com agentes externos visando ampliar a criatividade e a inovação, mas estabelecemos tais contextos como um caso típico em que as conexões com terceiros são úteis para esse propósito. Ainda, nossa análise não busca uma visão excludente, o entendimento da criatividade e da inovação pode ser ampliado por outras perspectivas. O que defendemos é uma possibilidade complementar.

Ao longo do tempo, a inovação deixou de ser executada apenas internamente e passou a ser complementarmente conduzida com parcerias de agentes de outras organizações, a chamada inovação aberta (CHESBROUGH, 2006). Aqui discutimos uma fase anterior à inovação, ou seja,

\footnotetext{
${ }^{1}$ Universidade Federal de Pernambuco (UFPE), Recife, Pernambuco, Brasil.
} 
a criatividade, expandindo a análise para a criatividade originada ou influenciada por agentes externos, daí sua denominação aberta. Isso é pertinente nesse momento em virtude do reconhecimento de que a criatividade é um processo que antecede à inovação (CANIËLS; STOBBELEIR; CLIPPELEE, 2014), que pode ser gerenciado (MUZZIO, 2017) e que pode tornar mais efetiva a prática da inovação aberta. Com isso, identificamos uma lacuna na literatura que é a compreensão de como ocorre a criatividade aberta, quais são os comportamentos facilitadores desse fenômeno e como ele pode afetar a geração de ideias. Essa compreensão é importante para gestores porque tem o potencial de alavancar a criatividade quando esse conhecimento for aplicado em suas práticas cotidianas. Para acadêmicos, isso é pertinente por contribuir na compreensão das condições, dos tipos e das implicações dessa prática, ampliando o conhecimento do fenômeno criatividade. Nessa ordem, os insights aqui analisados são importantes para superar o conhecimento teórico e o potencial prático disponíveis que, no caso da criatividade, ainda apresenta uma lacuna de conhecimento quando se trata de compreender o seu processo (FORTWENGEL; SCHÜßLER; SYDOW, 2017). Essa análise é importante também no momento, em razão do crescente número de profissionais que trabalham em espaços de coworking, constituindo-se em uma nova forma de fazer negócio que permite maior integração profissional de distintas expertises. Nesse sentido, a criatividade também passa a ser influenciada pelas conexões ali estabelecidas, o que faz emergir uma lacuna na literatura sobre a compreensão de como esse novo contexto de trabalho coletivo influencia a criatividade.

Diante de uma realidade em que há grande geração de ideias e que muitas podem ser inúteis, sem valor de mercado e sem utilidade para usuários, Frederiksen e Knudsen (2017) afirmam que é pertinente uma análise criteriosa para buscar identificar aquelas com maior potencial de gerar inovação, mesmo não sendo uma tarefa fácil. Essa posição corrobora com uma visão de significativa importância da criatividade por funcionar como um primeiro guardião de ideias que efetivamente vão gerar produtos úteis, valorizados e com potencial de competitividade no mercado. Reconhecendo essa importância, destacamos a pertinência de entender esse fenômeno em uma dimensão exterior ao contexto clássico de gerar ideias internamente, valendo-se, para isso, de uma realidade social e de mecanismos que facilitam as trocas de conhecimentos.

Ao longo do tempo, os relacionamentos organizacionais mudaram, e hoje se estabelecem novos vínculos, acompanhando a dinâmica social. Comunicação remota, internet das coisas, digitalização, inteligência artificial, compartilhamento etc. São exemplos de meios, de estratégias ou de tecnologias que têm revolucionado a maneira de se relacionar dentro das organizações e entre organizações ou profissionais. Tais condições ocorrem em um contexto em que prevalece um sistema de espaço de fluxo e de rede mundial diante do anterior sistema de espaço de lugar (CASTELL, 1996) e sob as lentes de um capitalismo cultural cognitivo que provoca grandes transformações nas relações sociais dos centros urbanos (SCOTT, 2011).

A lógica do uso coletivo e aberto para encontrar soluções para os desafios contemporâneos por meio de parcerias com agentes externos tem se intensificado (BOGERS; CHESBROUGH; MOEDAS, 2018). Tal prática tem sido utilizada tanto no desenvolvimento de produtos, exemplificado no sistema computacional Linux, como em parcerias em contextos urbanos (HÉRAUD, 2016), exemplificado nos clusters ou em coworkings, bem como, no universo organizacional (PILAV-VELIC; MARJANOVIC, 2016; SCOZZI; BELLANTUONO; PONTRANDOLFO, 2017). Empresas também têm recorrido a aceleradoras de inovação, caracterizadas por startups parceiras que 
se valem de suas caraterísticas mais dinâmicas e criativas, para ampliar a inovação disruptiva (RICHTER; JACKSON; SCHILDHAUER, 2018).

A literatura (INKPEN; TSANG, 2005; ZHOU; LI, 2012; AKHAVAN; HOSSEINI, 2015; OLLILA; YSTRÖM, 2016; PERRY-SMITH; MANNUCCI, 2017) reconhece a importância do compartilhamento de informação por meio de redes de relacionamentos individuais e organizacionais, o que permite o acesso a conhecimentos essenciais ou estratégicos pertencentes a terceiros. Esse procedimento está vinculado diretamente ao que é chamado de capital social, em que as redes de relacionamento possuem um papel preponderante na consolidação desse conceito (PERRYSMITH; SHELLEY, 2003). A teoria do capital social trabalha na perspectiva de que as organizações são capazes de ampliar suas inovações e vantagens competitivas através da criação e do compartilhamento de conhecimento. Nahapiet e Ghoshal (1998) tratam o capital social como um acúmulo de recursos reais, e potenciais, que são disponibilizados por, ou são derivados de uma rede de relacionamento. Esse capital corresponde tanto a rede em si, como aos diversos ativos que podem ser mobiliados por meio dessa estrutura.

Essa perspectiva está ancorada na concepção de que as firmas podem, e devem, usar ideias e conhecimentos tanto internos, como externos, para o desenvolvimento de novos conceitos e novas aplicabilidades (CHESBROUGH, 2006, WEST; BOGERS, 2014). A ação em rede também pode ser utilizada na perspectiva do indivíduo (INKPEN; TSANG, 2005) que pode se utilizar dos mesmos mecanismos válidos para as firmas, o que é útil para a análise da criatividade aberta em coworking. A conduta em rede é facilitada em função de haver muitas possibilidades de parcerias, desde indivíduos, passando por universidades a firmas concorrentes, por meio de parcerias informais e formais. Tal amplitude permite o uso dessa conduta por pequenos negócios, grandes corporações e profissionais autônomos. Os benefícios vão desde a redução de custos até ao acesso a tecnologias não disponíveis sem o uso de parcerias externas (WEST; BOGERS, 2014; HENKEL; SCHÖBERL; ALEXY, 2014).

Isto posto e diante do objetivo já evidenciado, apresentamos uma discussão realizada a partir de uma pesquisa bibliográfica que analisa as potenciais condições de ocorrência, os mecanismos de prática e as implicações para o uso da criatividade aberta. Para isso, desenvolvemos mais quatro seções. A primeira analisa a inovação e a criatividade sob a ótica aberta. Em seguida, discutimos características dos coworkings, aqui utilizados como um exemplo singular de facilitação da criatividade originada em agentes externos. A próxima seção apresenta a discussão analítica sobre a criatividade aberta. Em seguida, são elaboradas as considerações finais com direcionamentos de pesquisa para o desenvolvimento desse emergente campo.

\section{INOVAÇÃO ABERTA E CRIATIVIDADE ABERTA}

A inovação tem a capacidade de proporcionar transformações na sociedade, e sempre foi basilar para a competitividade das firmas, o que lhe colocou como tema de grande interesse para acadêmicos e gestores. Ela pode ocorrer tanto por ações internas, como externas, estratégias essas que devem ser vistas como complementares, e não como concorrentes (DAHLANDER; GANN, 2010).

A inovação pode ser vinculada à capacidade inventiva da firma, que está relacionada a ações internas para gerar conhecimento, e, por outro lado, à capacidade absortiva, que está vinculada à absorção do conhecimento no nível extra firma (LICHTENTHALER, 2011). Nessa ordem, a inovação aberta, tanto pode ocorrer no sentido organização-exterior, como no sentido exterior-organização (BOGERS; CHESBROUGH; MOEDAS, 2018). 
Essas possibilidades evidenciam a mudança no escopo deste fenômeno ao longo do tempo. Inicialmente, a inovação estava prioritariamente associada à ação interna da firma. Baseado em princípios como o segredo industrial ou a busca por recursos únicos, essas firmas procuravam desenvolver suas inovações por meio de recursos internos para garantir uma vantagem competitiva sustentável. Sem desconsiderar a pertinência da inovação interna, no decorrer do tempo, outras perspectivas emergiram, mais condizentes com uma economia baseada na tecnologia da informação, na facilidade de comunicação e na valorização do compartilhamento social (GRANADOS; BERNARDO; PAREJA, 2017).

Nesse processo, surge a inovação aberta, que vem se consolidando como um campo de conhecimento capaz de evidenciar as características e as condições específicas que permitem as organizações atuarem para além de suas fronteiras, por meio de parcerias das mais distintas para incrementar a inovação (OLLILA; YSTRÖM, 2016). Chesbrough e Bogers (2014, p. 27) definem inovação aberta como "um processo de inovação distribuído baseado em fluxos de conhecimento propositadamente gerenciados através de fronteiras organizacionais, utilizando mecanismos pecuniários e não pecuniários, em consonância com o modelo de negócios de cada organização".

West e Bogers (2014) comentam sobre os três principais processos recíprocos de inovação encontrados na literatura. Os autores destacam a concriação, a forma mais usual, que normalmente é estabelecida entre parceiros por meios de acordos que viabilizam a colaboração conjunta em um amplo escopo de possibilidades. O segundo destaque é a atuação em rede, no qual as organizações se filiam a uma estrutura coletiva de colaboração. Por fim, indicam as comunidades, que são associações abertas de indivíduos e/ou organizações que se diferenciam das redes em função de haver uma identidade e uma fidelidade entre seus membros. Em cada um desses tipos, é possível a identificação de níveis de colaboração que proporcionam crescentes parcerias e exploração das características da atuação conjunta para incrementar a inovação.

Quanto à criatividade, esta é reconhecida na literatura sua estreita relação com a inovação (CANIËLS; STOBBELEIR; CLIPPELEE, 2014). Criatividade organizacional pode ser definida como a capacidade coletiva que proporciona rupturas conceituais ou práticas, possibilita a disponibilidade de novos processos, conceitos, serviços ou produtos para a aplicação comercial (MUZZIO, 2017), e que apresenta novidade, utilidade e valorização (AMABILE, 1995).

Perry-Smith e Mannucci (2017) distinguem o processo criativo e inovador em quatro fases interconectadas que ocorrem em um processo contínuo por meio de redes com laços fracos e fortes, com intensa ação social. A fase de geração de ideia, na qual é necessária uma flexibilidade cognitiva; a fase de elaboração de ideia, em que se trabalha para deixar a ideia original mais clara e desenvolvida, como exemplificada na elaboração de um protótipo; a fase de defesa da ideia, na qual há uma ação de influência e legitimidade para garantir recursos; e a fase da implementação da ideia, em que ocorre a tangibilidade dessa ideia ou um produto finalizado.

Este artigo defende que a criatividade é um fenômeno distinto da inovação (BAER, 2012), ainda que com estreita relação entre ambos, e, nesse sentido, pode ser conduzida por meio de uma gestão específica para melhor eficiência da aplicabilidade dos resultados oriundos desse processo (MUZZIO, 2017).

Essa distinção entre criatividade e inovação como fenômenos interdependentes não exclui a possibilidade de mecanismos vinculados existirem em ambas as etapas do processo de inovar. Nessa ordem, o conhecimento sobre a criatividade aberta pode se valer de princípios da inovação aberta para se desenvolver e configurar-se como um campo de conhecimento complementar, 
o que pode potencializar a própria inovação, dado que um processo criativo mais eficaz amplia a possibilidade de inovação, ao disponibilizar ideias com maior potencial de aplicação por meio de produtos úteis, valorizados pelo mercado e potencialmente competitivos (FREDERIKSEN; KNUDSEN, 2017).

São exemplos de agentes externos que podem atuar na criatividade aberta: Os consumidores, os institutos de pesquisa, os fornecedores, os consultores, os atores diversos do mercado, e mesmo os concorrentes, todos eles potenciais fornecedores de valiosos insights, competências ou tecnologias que significariam custos ou tempo excessivos se desenvolvidos internamente, ou mesmo, se fizessem uma simples aquisição externa (GRECO; GRIMALDI; CRICELLI, 2016; SCOZZI; BELLANTUONO; PONTRANDOLFO, 2017).

O processo da criatividade aberta é facilitado por condições emergentes no mercado que favorecem a troca de dados, informações e insights, a destacar: Uma extensa rede de colaboração baseada na comunicação remota, uma oferta crescente de ambientes físicos coletivos que comportam profissionais de diversos segmentos, possibilitam a ampliação de relações sociais, e um comportamento de compartilhamento de bens, serviços e informações, fenômeno esse que tem emergido com uma nova classe de profissionais vinculados à economia criativa (FLORIDA, 2011; GANDINI, 2015).

Tal como a inovação aberta é considerada um tipo de inovação, o fenômeno da criatividade aberta pode ser classificado como um tipo de criatividade; assim, é preciso compreendermos quais condições são mais favoráveis para que ele se intensifique, quais contextos podem permitir sua maior eficiência e quais mecanismos podem contribuir para sua ampliação. Especificamente sobre os ambientes em que essa criatividade aberta pode ser mais efetiva, o coworking é um caso típico em razão de suas características. Nesse sentido, a próxima seção apresenta uma discussão sobre esses espaços e suas potencialidades para facilitar esse fenômeno.

\section{OS ESPAÇOS DE COWORKING}

Os coworkings constituem espaços de trabalho coletivo, nos quais os usuários podem atuar de forma flexível em termos de horários, de lugares físicos e de equipamentos de trabaIho. Normalmente, deles participam profissionais de diversos campos do conhecimento, que se integram em ambientes físicos que proporcionam infraestrutura compartilhada, e podem levar a inovações (CAPDEVILA, 2016). A redução de custos para seus clientes é uma característica, porém seus benefícios podem ser muito mais estratégicos e significativos, a partir das relações que ali podem se estabelecer, ou seja, há uma vantagem de atuar nesse tipo de negócio, em virtude da potencialidade que essa rede de profissionais pode proporcionar, a partir das relações socioeconômicas desenvolvidas.

Esses espaços funcionam normalmente como uma comunidade, definida como uma associação voluntária de indivíduos ou organizações, que vão além de uma atuação em rede, por se vincularem por meio de amizade, de identidade e de fidelidade (WEST; BOGERS, 2014), condição potencializadora de maior integração e geração de ideias.

O Coworking, ancorado na perspectiva de inovação social, permite a colaboração, o compartilhamento de conhecimento, o aprendizado mútuo e oferece oportunidades para alcançar acordos comerciais entre seus participantes.

Fabbri e Charue-Duboc (2016) investigaram três coworkings franceses e evidenciaram a efetividade desses espaços como vetores de ampliação e estímulo à inovação aberta. Eles 
ressaltaram a importância das relações físicas, ainda que permeadas pela tecnologia, que esses espaços proporcionam, ao conjugarem diferentes profissionais, e permitirem as dinâmicas colaborativas físicas que amplificam tanto a criatividade como a inovação.

É crescente o interesse no uso do coworking no mundo. De acordo com Deskmag (2018), a expectativa para o final do ano de 2018 é que cerca de 1.700 .000 pessoas atuarão nesses espaços. No Brasil, também é significativo a ampliação de seus usuários. Segundo o Coworking Brasil (2017), havia em março de 2017 cerca de 810 unidades cadastradas, o que representava um incremento de mais de $114 \%$ em relação ao ano anterior, e com expectativa de continuidade nessa trajetória ascendente.

Os coworkings são uma boa representação de formatos de negócios inovadores, de ações organizacionais baseadas em novos contextos da era informacional e de estratégias gerenciais ancoradas em novos meios de criação do conhecimento. Esses espaços promovem uma base institucional comum, que reduz as distâncias cognitivas e facilita a comunicação, ampliando a possibilidade de colaboração coletiva, de criatividade e de inovação. Esse contexto tem o potencial de facilitar a geração do conhecimento que, segundo Nonaka e Takeuchi (2008), envolve a ação social de transformação de conhecimento tácito em conhecimento explícito. Assim, no coworking, há uma maior possibilidade da geração e da transferência de conhecimento tácito de terceiros, em razão da facilitação de comunicação com atores de outros campos do conhecimento e de outras organizações.

Isso é potencializado em razão de esse espaço estar relacionado a um novo perfil profissional, formado por atores da economia do conhecimento que buscam estabelecer novas relações de práticas colaborativas e de compartilhamento dessas expertises (GANDINI, 2015).

Hitters e Richards (2002) reconhecem que o contato informal em ambientes organizacionais coletivos, como o coworking, pode criar uma atmosfera positiva e efeitos sinérgicos, possibilitando a ampliação da inovação e a criação de pontes entre o local e o global. As organizações e os profissionais que se voltam para a atuação no modelo de coworking optam por não agir em uma perspectiva de intramuros, mas, sim, em uma convivência direta com outros agentes econômicos, inclusive concorrentes. Isso significa uma mudança de paradigma que impacta no comportamento organizacional, na forma de relacionamento com consumidores e na maneira de se posicionar no mercado (JAW, CHEN; CHEN, 2012).

A concentração de atividades em espaços específicos nos centros urbanos oferece oportunidades para que os trabalhadores criativos acessem a essas redes locais, facilitando, assim, a transmissão do conhecimento sobre o emprego, e às tendências do mercado através de uma intensa interação face a face (VINODRAI, 2013).

Nessa visão, o coworking representa uma nova fronteira na forma de profissionais liberais, autônomos, artistas e pequenas empresas fazerem negócios, tendo a estratégia de atuação em rede (GRANOVETTER, 1973), um forte componente estrutural (INKPEN; TSANG, 2005). Tal contexto tem o potencial de favorecer a criatividade aberta, ao permitir a intensidade de conexões sociais e mercadológicas, que subsidiarão o processo de geração e aprimoramento de ideias.

\section{OS ESPAÇOS DE COWORKING E A PROPOSIÇÃO TEÓRICA DA CRIATIVIDADE ABERTA}

De acordo com Capdevila (2015), as pesquisas sobre inovação têm negligenciado a microescala de análise, composta pelo nível individual (empreendedores, freelances e autônomos), por microfirmas ou comunidades, onde, segundo o autor, enquadram-se os espaços de coworking. 
Granovetter (1973) evidenciou, de forma seminal, o potencial dos laços fracos em uma estrutura de redes. Nesse sentido, a criatividade aberta tem maior probabilidade de ocorrer nas fronteiras de grupos interdisciplinares, do que em suas partes centrais (PERRY-SMITH; SHELLEY, 2003), bem como, por meio dos laços fracos (PERRY-SMITH; MANNUCCI, 2017), exatamente onde ocorre maior integração de diferentes campos do saber, possuindo assim maior chance de congregar conhecimentos complementares para gerar inovação (VISSERS; DANKBAAR, 2002). Tal perspectiva é evidenciada no coworking, no qual os laços fracos entre profissionais tendem a ampliar a criatividade de origem externa.

Esses espaços funcionam como um nó da rede, tanto no aspecto físico, como na perspectiva simbólica, com isso, potencializam interfaces e tornam-se um importante mecanismo de difusão de ideias e conceitos que irão alimentar o processo criativo e a inovação (FABBRI; CHARUE-DUBOC, 2016). Isso é condizente com a ideia de que profissionais participantes de densas redes transacionais, dos mais variados tipos, estão em uma posição mais favorável para adquirir informações úteis e explorar suas amplas potencialidades, se comparados àqueles que são socialmente mais isolados (SCOTT, 2014), posição convergente com a de Hall (1996), para quem a densidade, a interação humana e a sinergia são fundamentos essenciais da criatividade. Ou ainda, com o trabalho de Héraud (2016), que evidencia um repertório social cognitivo desenvolvido em comunidades vinculadas a determinados territórios, como significativos para uma criatividade coletiva.

Os coworkings são espaços abertos nos quais profissionais portadores de distintas expertises acabam por conviver, ou seja, tais contextos proporcionam ambientes de interação facilitadores para a troca de conhecimentos complementares que, assim, podem se recombinar e ampliar a geração de ideias, uma ação basilar da criatividade. O capital social individual, evidenciado nesses espaços, funciona como um potencializador dos fluxos de conhecimento, ação facilitada por convergência de objetivos ou lógicas subjetivas culturais e por uma convivência mais intensa (INKPEN; TSANG, 2005).

Esses espaços também possuem a característica de congregar indivíduos que se vinculam a uma nova perspectiva socioeconômica. Isso imputa um forte conteúdo simbólico a quem dele participa. Além de compartilhar um ambiente físico, a presença ali significa uma forma de relacionamento, ou uma maneira de vivência, que valoriza a condição social do compartilhamento, da troca, por vezes, sem o envolvimento de remuneração financeira.

A partir dessa integração, os profissionais podem agir ativamente para ampliar a criatividade. Trata-se de um comportamento convergente com o processo de inovação aberta, porém, também não imune a condições de incerteza, tais como regras não tão claras, alta tolerância a ambiguidade, independência de estratégias, riscos, apostas paralelas e tolerância para falhas, o que torna essa iniciativa ainda mais incerta quanto a resultados efetivos (OLLILA; YSTRÖM, 2016). Isso corrobora com Garud, Tuertscher e Van de Vem (2015) que arguem que o processo inovador e o de geração da criatividade não é normalmente sequencial, mas, sim, um percurso imprevisível e incontrolável, o que coloca sua gestão sobre uma perspectiva de ambiguidade e incerteza. Ainda assim, podemos supor que as externalidades positivas superam essas adversidades.

A maneira como a criatividade aberta ocorre guarda relação com o processo de inovação aberta, mas é de natureza mais subjetiva e tácita (NONAKA; TAKEUCHI, 2008). Analisando a inovação aberta, Scozzi, Bellantuono e Pontrandolfo (2017) indicam meios de relação da rede de contatos facilitadores desse processo, a saber: O modo de acesso, o grau de formalidade, os 
incentivos, o modo de interação, o fluxo de informação, o lócus de controle, o modo de coordenação, a acessibilidade de saída e a forma de coordenação. Em complemento, Ollila e Yström (2016) apresentam os princípios de design da inovação aberta e destacam: A presença de participantes de igual influência, a diversidade como fonte de criatividade, as múltiplas identidades dos participantes, um propósito maior que une os participantes e a colaboração entre os integrantes.

Esses comportamentos e atitudes também podem ser ativados na criatividade aberta. Eles evidenciam mecanismos colaborativos, heterogêneos, multidisciplinares, diversificados etc. que são basilares na ação criativa aberta. Nos coworkings, essa ação pode ser conduzida tanto de maneira formal como de maneira informal. No primeiro caso, há uma ação efetiva dos agentes para ampliar suas criatividades quando se congregam a terceiros em parcerias. No segundo caso, ainda que não exista uma parceria estabelecida, a presença nesses contextos facilita as trocas de capital social, que Nahapiet e Ghoshal (1998) associam à soma de recursos atuais e potenciais disponíveis através de ou derivados de uma rede de relacionamento no nível individual ou coletivo. Esse capital possibilita o acesso a ideias, a modelos ou a práticas que acabam sendo incorporadas ou adaptadas, contribuindo para uma maior criação de ideias, ou seja, a efetivação da criatividade aberta.

Os insights criativos ocorrem pela recombinação de ideias e artefatos entre diferentes expertises (KRATZER; LETTL; FRANKE; GLOOR, 2016), tanto em sua dimensão de amplitude, como na dimensão de profundidade, a primeira, mais vinculada à inovação incremental, e a última, com a maior possibilidade de gerar inovação radical (ZHOU; LI, 2012). Reiter-Palmon, Wigert e Vreede (2012) destacam a influência positiva da diversidade funcional (formação, expertises, trajetórias de experiências profissionais) sobre a ampliação da criatividade. Os autores avaliam ainda como potencialmente positiva a mudança de membros de equipes no decorrer do tempo, pois isso evidenciaria uma maior diversidade e seus efeitos benéficos. Essas condições facilitam o pensamento divergente, um conceito básico para a geração de ideia. Embora esses autores falem de equipes organizacionais, esses princípios podem ser extrapolados para os espaços de coworking. Nesse caso, a diversidade não viria por uma equipe pertencente a uma organização específica, mas sim, em função dos vários profissionais usuários. Igualmente, a mudança da equipe não viria por substituições organizacionais, mas em razão da dinâmica de mudança de usuários, característico desse ambiente.

A figura 1 ilustra a perspectiva teórica aqui desenvolvida. Nela, a criatividade aberta em coworking ocorre com intercâmbio com o ambiente (simbolizado pelas linhas tracejadas). Internamente, as relações entre os indivíduos (de 1 até n) são permeadas por relações físicas e digitais, favorecidas por uma visão de comunidade de seus usuários (WEST; BOGERS, 2014). Por meio dessas relações, há uma intensa troca de ideias, de conceitos, de capital social (NAHAPIET; GHOSHAL, 1998), de conhecimento tácito (NONAKA; TAKEUCHI, 2008) e de repertório social cognitivo (HÉRAUD, 2016) que transitam entre os indivíduos em constante retroalimentação. Essas trocas operacionalizam a criatividade aberta. Ao receber insights por meio de parcerias formais ou mesmo por influência de outros agentes do coworking, esses indivíduos ampliam a geração de ideias originada de terceiros. Ao pertencer a outros campos de conhecimento, os profissionais parceiros evidenciam a condição de laços fracos e o consequente potencial para geração de ideias (PERRY-SMITH; MANNUCCI, 2017) por complementaridade. 
Figura 1- Proposição teórica da criatividade aberta

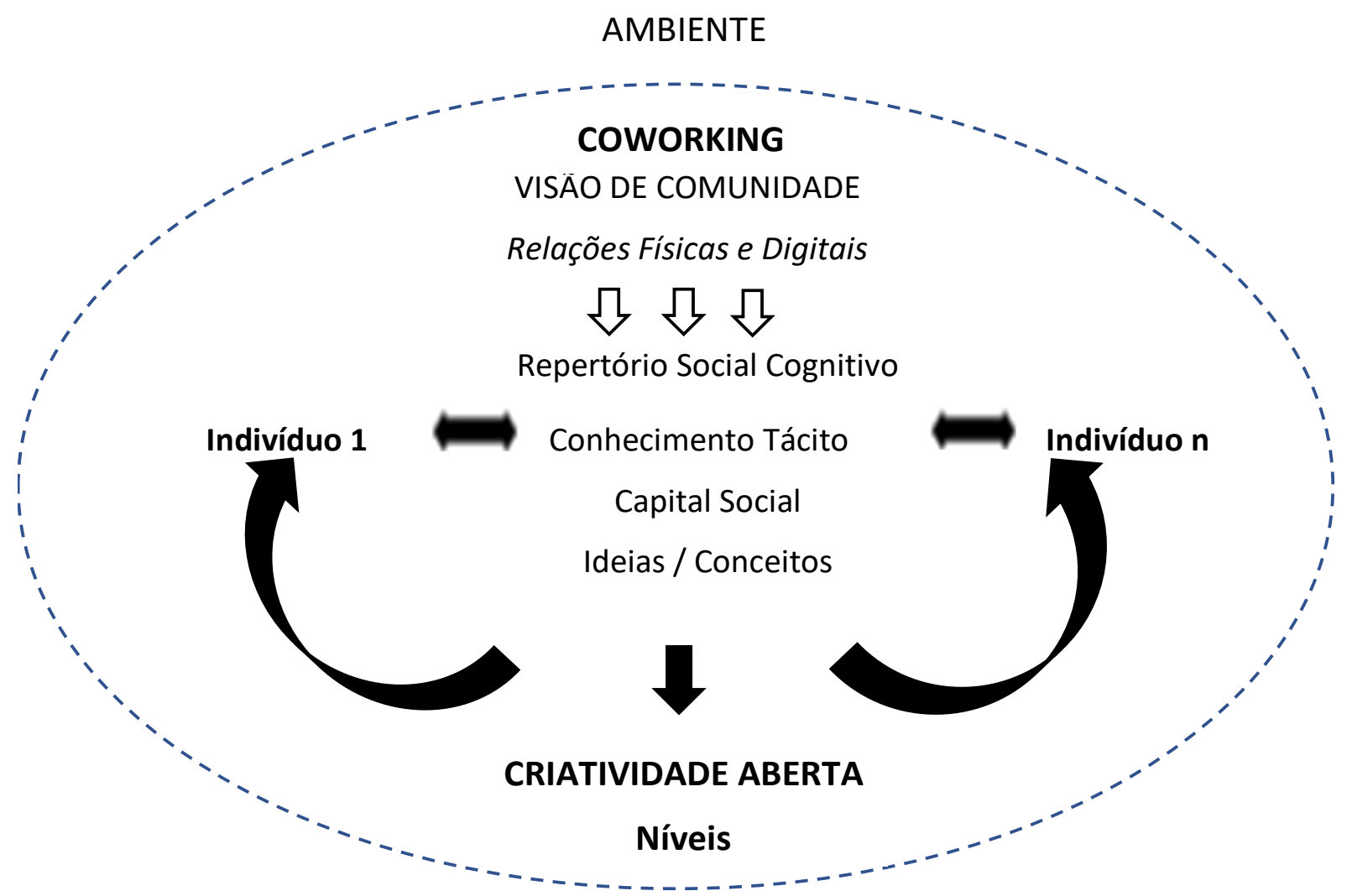

Fonte: Elaborado pelo autor

A criatividade aberta em ambientes de coworking ocorre em quatro níveis, que se diferenciam em função do grau de transferência de conhecimento e em razão da formalidade dessa transferência. Um primeiro nível é Influência de Terceiros: O indivíduo é influenciado por ideias, práticas ou modelos de outros atores da rede, favorecido pela simples proximidade por atuar no coworking. O segundo nível é Apoio de Terceiros: O indivíduo recebe apoio informal, dicas, insights de outros atores da rede, favorecido por relações fracas estabelecidas no coworking. O terceiro nível é Parceria com Terceiros: O indivíduo forma parcerias temporais/transitórias e recebe conhecimento, expertises, insights de atores da rede, favorecido por relações fracas e objetivos comuns transitórios estabelecidas no coworking. O último nível é Associações com Terceiros: O indivíduo recebe formalmente a transferência de tecnologia, know-how ou conhecimento estruturado de atores da rede, favorecido por relações fortes estabelecidas nesse contexto.

A lógica das trocas nos coworkings ocorre de maneira semelhante a comunicações remotas. Nesse caso, o facilitador do processo criativo não é exclusivamente a tecnologia de comunicação, mas, sim, a proximidade física e as relações estabelecidas por essa condição. As trocas representativas da criatividade aberta podem envolver relações pecuniárias ou não, evidenciando uma condição peculiar dessa criatividade, que é a possibilidade de ser realizada sem o envolvimento de contratos ou pagamentos, simplesmente pelas relações de proximidade ou das trocas voluntárias, associadas a um novo comportamento social de compartilhamento (HÉRAUD, 2016).

Granados, Bernardo e Pareja (2017) defendem que as ideias provêm de quatro fontes: da criatividade individual, do mercado, da ciência e do trabalho coletivo/interação com terceiros. No contexto do coworking, a criatividade aberta está mais associada a essa última categoria quando comparado a outros contextos de desenvolvimento de ideias. 
Para que essas trocas sejam mais efetivas, a capacidade absortiva (COHEN; LEVINTHAL, 1990) dos indivíduos deve ser ampliada, ou seja, a capacidade de identificar, de assimilar, de transformar e de aplicar conhecimentos externos, caso seja intensificada, amplia a criatividade aberta. Ao possuir previamente conhecimentos e habilidades relevantes, o indivíduo gera criatividade com sua capacidade absortiva, permitindo tipos de associações e vínculos que podem nunca ter sido considerados antes (COHEN; LEVINTHAL, 1990).

Essa estratégia tem potencial de alavancar a criatividade dos usuários de coworking e corrobora com uma realidade de crescente importância desses espaços na participação de mercado (DESKMAG, 2018), nas configurações mercadológicas dos territórios (HÉRAUD, 2016) na criatividade e inovação (FABBRI; CHARUE-DUBOC, 2016) e na atuação em comunidades (WEST; BOGERS, 2014).

Embora estejam presentes em um coworking, esses profissionais não estão isolados do ambiente global. A partir de uma rede de relações (CASTELL, 1996) na qual é possível superar questões físicas, esses indivíduos também atuam no ciberespaço e se valem dele como um poderoso meio para a interação social e para a troca de conhecimento, ou seja, a análise da criatividade aberta no contexto de coworking atua por complementariedade entre o físico e o virtual, sendo esse espaço um catalisador desses dois tipos de conexões, que viabilizam e ampliam a criatividade aberta e suas externalidades positivas.

\section{CONSIDERAÇÕES FINAIS}

West e Bogers (2014) afirmam que não está muito claro como as inovações abertas se deslocam do ambiente externo para um produto comercial através do modelo de negócios da empresa, e mais, em que medida esse processo requer estratégias de inovação distintas. Isso nos exemplifica o quão é desafiador para acadêmicos e gestores, dominar as especificidades e o real alcance da inovação aberta, o que podemos estender à criatividade aberta. Mas o reconhecimento da pertinência de sua aplicação deve ser um indutor para superar essa lacuna.

O objetivo deste trabalho foi apresentar uma proposição teórica sobre a criatividade aberta. Desenvolvemos conexões que buscam explicar essa nova fronteira do conhecimento, destacando práticas e tipos de interação entre os profissionais que tornam a criatividade aberta mais efetiva. Ao reconhecermos a criatividade aberta como um fenômeno desvinculado da inovação aberta, desbravamos um novo caminho de pesquisa que é útil para pesquisadores e gestores. Para os primeiros, a criatividade aberta indica um campo de investigação para explicar como a interação com agentes externos influencia a geração de ideias. Para os gestores, esse conhecimento pode subsidiá-los na tomada de decisões que signifiquem mais efetividade da geração de ideias e a ampliação de suas externalidades positivas.

A proposição da criatividade aberta deve ser vista como complementar à inovação aberta, ambas contribuindo para ampliar o conhecimento sobre o macrofenômeno da inovação. Igualmente, a criatividade aberta deve ser vista como complementar ao processo tradicional de criatividade realizada internamente, pois ambas são pertinentes para a ampliação da geração de ideias, assim também como a inovação aberta deve ser vista como complementar à inovação interna (DAHLANDER; GANN, 2010).

A nova maneira de atuar experienciada por diversos profissionais, por meio de participação em comunidades, sendo o coworking um ponto de conexão, pode significar mudanças 
estruturais nas práticas dos negócios. A emergência desse modelo de organização espacial, conjugado com uma nova mentalidade dos profissionais que dele participam, faz surgir novas lacunas de compreensão dessa realidade, e a criatividade aberta é um exemplo que contribui para superar essas lacunas.

A análise aqui desenvolvida é de cunho teórico; nesse sentido, um caminho indicativo sobre trabalhos posteriores é o desenvolvimento de pesquisas empíricas para consolidação do entendimento sobre a criatividade aberta nas diversas realidades sociais. Nesse sentido, pesquisas em contextos da economia criativa, ou em organizações que atuam com a geração externa de ideias, devem ser incentivadas para o avanço desse campo de conhecimento.

Essa análise se deteve em coworking, mas a criatividade aberta pode ocorrer em diferentes contextos sociais e mercadológicos. Nessa ordem, outro caminho de pesquisa possível é a compreensão desse fenômeno em distintos contextos macroeconômicos. Por exemplo, elucidar como a criatividade aberta se desenvolve nas relações entre grandes corporações, ou ainda, como a criatividade aberta é influenciada por diferenças culturais quando as parcerias envolvem relações interculturais. Especificamente nos coworkings, pesquisas podem, ainda, elucidar o impacto do quantitativo de profissionais nesses ambientes e a diversidade de campos de conhecimento sobre a criatividade aberta entre seus membros.

\section{REFERÊNCIAS}

AKHAVAN, P.; HOSSEINI, S. M. Determinants of knowledge sharing in knowledge networks: a social capital perspective. IUP Journal of Knowledge Management, v. 13, n. 1, p. 7-24, 2015.

AMABILE, T. M. Attributions of creativity: what are the consequences? Creativity Research Journal, v. 8 , n. 4, p. 423-26, 1995.

BAER, M. Putting creativity to work: The implementation of creative ideas in organizations. Academy of Management Journal, v. 55, n. 5, p. 1102-19, 2012.

BOGERS, M.; CHESBROUGH H.; MOEDAS C. Open innovation: research, practices, and policies. California Management Review, v. 60, n. 2, p. 5-16, 2018.

CANIËLS, M. C. J.; STOBBELEIR, K.; CLIPPELEE, I. The antecedents of creativity revisited: a process perspective. Creativity and Innovation Management, v. 23, n. 2, p. 96-110, 2014.

CAPDEVILA, I. Une typ o lo g ie d'espaces ouverts d'innovation basee sur les differents modes d'innovation e t motivations a la participation. Gestion 2000, v. 33, n. 4, p. 93-116, 2016.

CAPDEVILA, I. Co-Working spaces and the localized dynamics of innovation in Barcelona. International Journal of Innovation Management, v. 19, n. 3, p. 1-28, 2015.

CASTELLS, M. The rise of the network society. The information age: economy, society, and culture. Oxford: Blackwell, 1996. V. I.

CHESBROUGH, H. W. The era of open innovation. Managing Innovation and Change, v. 127, n. 3, p. 3441, 2006.

CHESBROUGH, H. W.; BOGERS, M. Explicating open innovation: clarifying an emerging paradigm for understanding innovation. In: CHESBROUGH, H.; VANHAVERBEKE, W.; WEST, J. (Ed.). New Frontiers in Open Innovation. Oxford: Oxford University Press, 2014. p. 3-28. 
COHEN, W. M.; LEVINTBAL, D. A. Absorptive capacity: a new perspective on learning and innovation. Administrative Science Quarterly, v. 35, n. 1, p. 128-52, 1990.

COWORKING BRASIL. Censo Coworking Brasil 2017. Disponível em: https://coworkingbrasil.org/ censo/2017. Acesso em: 20 abr. 2018.

DAHLANDER L.; GANN, D. M. How open is innovation? Research Policy, v. 39, n. 6, p. 699-709, 2010. DESKMAG. 2018. Disponível em: http://www.deskmag.com. Acesso em: 20 abr. 2018.

FABBRI J.; CHARUE-DUBOC, F. Les espaces de coworking nouveaux intermédiaires d'innovation ouverte? Revue Française de Gestion, v. 42, n. 254, 163-80, 2016.

FLORIDA, R. A Ascensão da classe criativa: e seu papel na transformação do trabalho, do lazer, da comunidade e do cotidiano. Porto Alegre: LPM, 2011.

FORTWENGEL, J.; SCHÜßLER, E.; SYDOW, J. Studying organizational creativity as process: Fluidity or duality? Creativity and Innovation Management, v. 26, n. 1, p. 5-16, 2017.

FREDERIKSEN, M. H.; KNUDSEN, M. P. From creative ideas to innovation performance: the role of assessment criteria. Creativity and Innovation Management v. 26, n. 1, p. 60-74, 2017.

GANDINI, A. The rise of coworking spaces: a literature review. Ephemera: Theory \& Politics in Organization, v. 15, n. 1, p. 193-205, 2015.

GARUD, R.; TUERTSCHER, P.; VAN DE VEM, A. Business innovation process. In: SHALLEY, C. F.; HITT, M. A.; ZHOU J. The Oxford Handbook of Creativity, Innovation, and Entrepreneurship. Oxford: Oxford University Press, p. 339-52, 2015.

GRANADOS, C.; BERNARDO, M.; PAREJA, M. How do creative industries innovate? A model proposal. Creative Industries Journal, v. 10, n. 3, p. 211-225, 2017.

GRANOVETTER, M. The strength of weak ties. American Journal of Sociology, v. 78, n. 6, p. 1930-38, 1973. GRECO, M.; GRIMALDI, M.; CRICELLI, L. An analysis of the open innovation effect on firm performance. European Management Journal, v. 34, n. 5, p. 501-16, 2016.

HALL, P. High-technology industry in the New York metropolitan area: a view from history, Annals of the New York Academy of Sciences, v. 787, p. 42-66, 1996.

HENKEL, J.; SCHÖBERL, S.; ALEXY, O. The emergence of openness: how and why firms adopt selective revealing in open innovation. Research Policy, v. 43, n. 5, p. 879-90, 2014.

HÉRAUD, J. A. A new approach of innovation: from the knowledge economy to the theory of creativity applied to territorial development. Journal of the Knowledge Economy, p. 1-17 , 2016.

HITTERS, E.; RICHARDS, G. The creation and management of cultural clusters. Creativity and Innovation Management, v. 11, n. 4, p. 234-47, 2002.

INKPEN, A. C.; TSANG, E. W. K. Social capital, networks, and knowledge transfer. Academy of Management Review, v. 30, n. 1, p. 146-65, 2005.

JAW, Y.; CHEN, C.; CHEN, S. Managing innovation in the creative industries- a cultural production innovation perspective. Innovation: Management, Policy \& Practice, v. 14, n. 2, p. 256-75, 2012. 
KRATZER, J.; LETTL, C.; FRANKE, N.; GLOOR, P. A. The social network position of lead users. Journal of Product Innovation Management, v. 33, n. 2, p. 201-16, 2016.

LICHTENTHALER, U. Open innovation: Past research, current debates, and future directions. Academy of Management Perspectives, v. 25, n. 1, p. 75-93, 2011.

MUZZIO, H. Indivíduo, liderança e cultura: evidências de uma gestão da criatividade. Revista de Administração Contemporânea, local , v. 21, n. 1, p. 107-24, 2017.

NAHAPIET, J.; GHOSHAL, S. Social capital, intellectual capital and the organizational advantage. Academy of Management Review, v. 23, n. 2, p. 242-66, 1998.

NONAKA, I.; TAKEUCHI, H. Teoria da criação do conhecimento organizacional. In: H. TAKEUCHI, H.; NONAKA, I. (Org.). Gestão do Conhecimento. Porto Alegre: Bookman, 2008. p. 54-90.

OLLILA, S.; YSTRÖM, A. Exploring design principles of organizing for collaborative innovation: The case of an open innovation initiative. Creativity and Innovation Management, v. 25, n. 3, p. 363-377, 2016.

PERRY-SMITH, J. E.; MANNUCCI, P. V. From creativity to innovation: the social network drivers of the four phases of the idea journey. Academy of Management Review, v. 42, n. 1, p. 53-79, 2017.

PERRY-SMITH, J. E.; SHALLEY, C. E. The social side of creativity: a static and dynamic social network perspective. Academy of Management Review, v. 28, n. 1, p. 89-106, 2003.

PILAV-VELIC, A.; MARJANOVIC, O. Integrating open innovation and business process innovation-insights from a large-scale study from a transition economy. Information \& Management, v. 53, n. 3, p. 398-408, 2016.

REITER-PALMON, R.; WIGERT, B.; VREEDE, T. de. Team creativity and innovation: the effect of group composition, social process, and cognition. In: MUMFORD, M. (Ed.). Handbook of organizational creativity. San Diego: Elsevier, 2012. p. 295-326.

RICHTER, N.; JACKSON, P.; SCHILDHAUER, T. Outsourcing creativity: an abductive study of open innovation using corporate accelerators. Creativity and Innovation Management, v. 27, n. 1, p. 69-78, 2018.

SCOTT, A. J. Beyond the creative city: cognitive-cultural capitalism and the new urbanism. Regional Studies, v. 48, n. 4, p. 565-78, 2014.

SCOTT, A. J. Emerging cities of the third wave. City: Analysis of Urban Trends, Culture, Theory, Policy, Action, v. 15, n. 3-4, p. 289-321, 2011.

SCOZZI, B.; BELLANTUONO, N.; PONTRANDOLFO, P. Managing open innovation in urban labs. Group Decision and Negotiation, v. 26, n. 5, p. 857-74, 2017.

VINODRAI, T. Design in a downturn? Creative work, labor market dynamics and institutions in comparative perspective. Cambridge Journal of Regions, Economy and Society, v. 6, n. 1, p. 159-76, 2013.

VISSERS, G.; DANKBAAR, B. Creativity in multidisciplinary new product development teams. Creativity and Innovation Management, v. 11, n. 1, p. 31-42, 2002.

WEST, J.; BOGERS, M. Leveraging external sources of innovation: A review of research on open innovation. Journal Product Innovation Management, v. 31, n. 4, p. 814-31, 2014.

ZHOU, K. Z.; LI, C. B. How knowledge affects radical innovation: knowledge base, market knowledge acquisition, and internal knowledge sharing. Strategic Management Journal, v. 33, n. 9, p. 1090-102, 2012. 


\section{Sobre o autor:}

Henrique Muzzio - Doutor em Administração pela Escola de Administração de Empresas de São Paulo (EAESP/FGV). Professor da Universidade Federal de Pernambuco (UFPE). E-mail: henrique.muzzio@ufpe.br, Orcid: http://orcid.org/0000-0002-9818-5810 